\title{
The split breast flap: Revisited - a medieval or an ideal solution in the selected case?
}

\author{
Andre DeGreef MD MB BCh MMed
}

\begin{abstract}
A DeGreef. The split breast flap: Revisited - a medieval or an ideal solution in the selected case? Can J Plast Surg 2011;19(3):99101.

In assessing a patient requiring palliative reconstruction of the anterior chest wall, a host of techniques engulf the reconstructive surgeon, who has to evaluate the local situation, the tissue lost, the tissue required and the tissue available. The patient's general condition is usually a major influence on this decision. The split breast flap is an often forgotten, simple means of palliative reconstruction.
\end{abstract}

Key Words: Chest wall reconstruction; Palliative; Split breast flap

$\mathrm{R}$ esection of advanced local breast tumours can result in large composite defects of the chest wall; however, there are many reconstruction options available. The problem associated with advanced, local, recurrent, malignant breast disease is finding a simple technique and solution that would resolve the problem of extensive local recurrence.

Frequently, the patient merely needs a palliative procedure to alleviate distressing symptoms and complications. The split breast flap is a simple, easy and time-saving procedure. Furthermore, it uses readily available local tissue and provides a fair-to-large volume of excellent quality local tissue. This flap is an example of a procedure that was used 50 years ago for the first time, but is currently rarely used. However, it is still relevant today and underscores the rich history our specialty has to fall back on in spite of the wondrous modern day developments.

\section{CASE PRESENTATION}

A 44-year-old Asian mother of a teenage boy and girl presented with a large smelly, fungating and bleeding mass in the region where a radical mastectomy was performed five years earlier (Figure 1). The diagnosis of ductal breast carcinoma was made at that time, and the patient and her husband, who was her senior by a few years, elected to only have the modified radical mastectomy with no adjuvant therapy. The patient presented with local chest wall recurrences 3.5 years after her mastectomy. These recurrences could have been excised, allowing primary closure of the arising defect. Again, the patient elected not to have any additional treatment. She developed recurrences one year later and was referred with a rapidly enlarging lesion on the anterior chest wall. Roentgenological evaluation performed at the time confirmed pulmonary evidence of widespread metastases and, in addition, total bony destruction of the anterior portions of the right fifth and sixth ribs. The fungating lobulated tumour on the patient's anterior chest wall measured $8 \mathrm{~cm} \times 7 \mathrm{~cm} \times 4 \mathrm{~cm}$, and extended over the midline to the left anterior chest wall. At the time of surgery, a resection of $13 \mathrm{~cm} \times 15 \mathrm{~cm}$ was performed. The anterior portions of the two affected ribs (fifth and sixth) were totally engulfed in the tumour mass and were, thus, removed en bulk with the tumour. The histology again confirmed recurrent ductal carcinoma. The postoperative phase was uneventful, with excellent healing.

During multiple preoperative visits, the patient expressed the intense desire to have this extremely painful, uncomfortable, smelly tumour removed regardless of the anatomical changes and appearances to her

\section{Le lambeau mammaire d'épaisseur partielle : une solution médiévale revisitée ou une solution idéale dans un cas sélectionné?}

Lors de l'évaluation d'un patient ayant besoin d'une reconstruction palliative de la paroi thoracique antérieure, le chirurgien reconstructif fait face à une pléthore de techniques et doit évaluer la situation, la perte tissulaire, les tissus requis et les tissus disponibles. L'état général de la patiente a généralement une énorme influence dans la décision. Le lambeau mammaire d'épaisseur partielle est un moyen simple et souvent oublié de reconstruction palliative. anterior chest wall contour. The mass bled constantly, and she had to change the dressing a few times a day. Her worst symptom, however, was that the necrotic lesion emitted such an offensive smell that she could immediately be recognized on entering a room.

The patient died six months after the split breast flap procedure due to fulminant florid pneumonia, without developing any further local chest wall recurrences. The surgical procedure consisted of the left breast being completely split in its full thickness, and inferiorly in the centre up to the nipple-areola complex, which was left intact. This provided enough local tissue to create the transposition flap to close the defect on the right anterior chest wall (Figure 2).

\section{DISCUSSION}

Thoracic wall defects have been termed as being either simple or of a compound variety. A simple defect involves the loss of the soft tissues of the chest wall, and a compound defect arises when the defect includes the loss of cartilage from the ribs and sternum or even from deeper structures such as the pleura and pericardium.

The causes of these defects may be numerous, with the neoplastic and traumatic variety accounting for most of these cases. A simple defect of the anterior chest wall can also evolve into a compound defect once infection or other complications arise.

Reconstruction of a large chest wall defect is totally dependent on the tissue available (1). In planning any reconstructive procedure, an assessment must be made of what is required to fulfill an adequate reconstruction and what tissues are readily available - the concept of 'robbing Peter to pay Paul'. The range or spectrum of surgical possibilities is extremely wide - from a split skin graft, which in one case was placed directly on the pericardium (2), to local flaps, regional flaps and tissue transfers using microvascular techniques. The split skin graft or Thiersch graft may be contraindicated due to a poor-receiving vascular bed, often due to previous irradiation of the region. In the event of a shortage of bone or cartilage in the defect, local flaps - such as the Serratus muscle/split rib graft - can be used (3).

Rib and periosteal flaps can be used in addition to large local flaps. In this situation, an adjacent rib is cut obliquely and its free end wired to the remnants of the remaining rib in the defect, thus traversing the defect and providing more support (4). A local flap then covers the rib and periosteal graft. Another local flap using the remaining breast, and inclusive of skin grafts and other local flaps, was used to cover large thoracic defects $(5,6)$. 


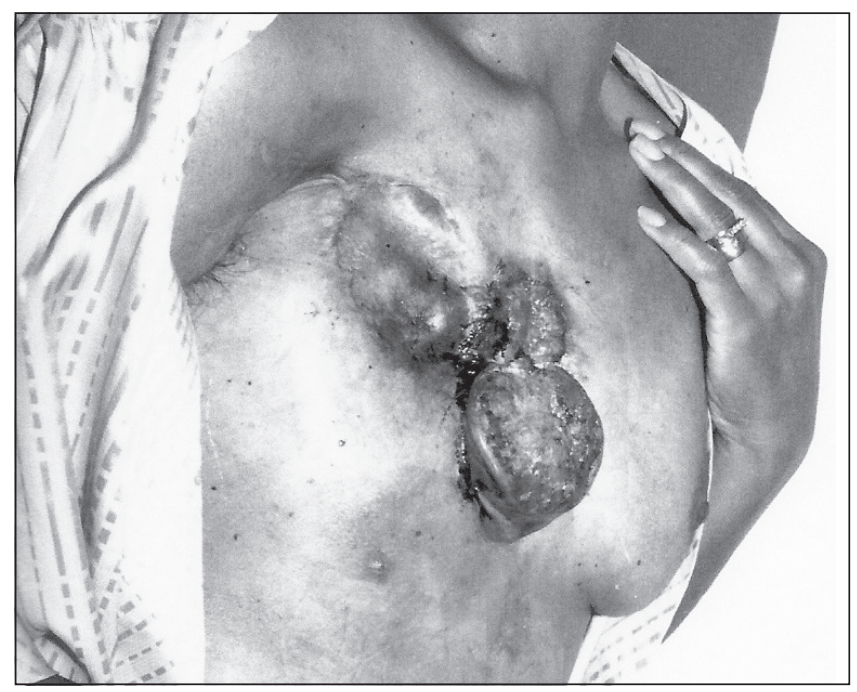

Figure 1) Patient at initial presentation with old mastectomy scar, skin graft and local recurrence visible

Skeletal resections often need to be performed depending on the cause of the problem. The resection of four to six ribs at the cartilagenous level has been described without the formation of a flail chest or the occurrence of respiratory insufficiency (7). In the event of previous irradiation, more 'stiffness' or rigidity was created due to fibrosis, thus allowing for the removal of more skeletal elements in the chest wall without collapse. Pleura has also been resected, on occasion, without actual replacement (3). If irradiation effects are grossly apparent in the surrounding tissues, a realistic anticipation must be made of the irradiation effects on the surrounding blood supply and tissues (8). Anyone experiencing the dread of seeing healthy viable imported tissue not binding to the irradiated tissue would understand this problem. This, in turn, should influence the decision as to what design the reconstruction should take. If a compound defect is present, lung physiology and capacity is evaluated, and we would attempt to predict the effect of the reconstruction (9).

Synthetic materials, such as Marlex polyethylene mesh (Chevron Phillips Chemical Company, USA), have been used by some authors to aid in stabilization; however, they have been severely criticized by others because of a high incidence of complications $(10,11)$. The use of local flaps often provide sufficient stability to the chest wall due to the fact that they are often thick and indurated, creating a stable frame. Chest wall stabilization should, thus, be considered mainly in massive structural defects (13). Another survey (8) considered reconstruction with vascularized nonirradiated tissue essential in patients undergoing aggressively wide resections. Free tissue transfers with microvascular anastomoses using muscle/composite flaps are frequently used as forms of reconstruction (8). Other reconstructions include latissimus dorsi muscle flaps covered with split skin, fasciocutaneous flaps, omental flaps,

\section{REFERENCES}

1. Whalen WP. Coverage of thoracic wall defects by a split breast flap. Plast Reconstr Surg 1953;12:64-73.

2. Pickrell KL, Baker HM, Collins JP. Reconstructive surgery of the chest wall. Surg Obs Gynec 1947;84:465-76.

3. Pers M, Medgyesi S. Pedicle muscle flaps and their applications in the surgery of repair. Br J Plast Surg 1973;26:313-21.

4. Mauer E, Blades B. Hernia of the lung. J Thorac Surg 1946;15:77.

5. Maier HC. Surgical management of large defects of the thoracic wall. Surgery 1947;22:169-78.

6. Pickrell KL, Kelly JW, Marzoni FA. Surgical treatment of recurrent carcinoma of the breast and chest wall. Plast Reconstr Surg 1948;3:156-72.

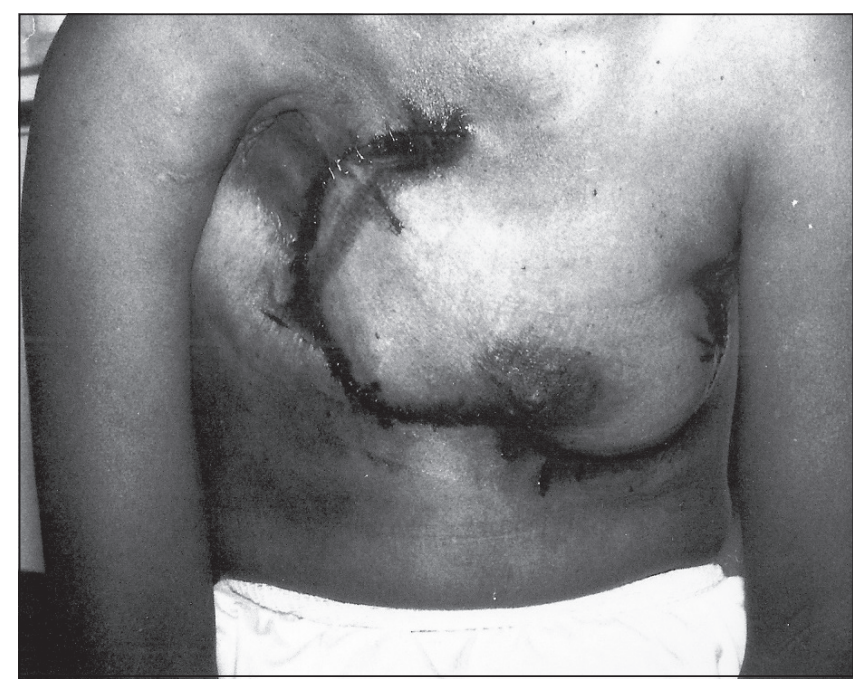

Figure 2) Appearance two weeks after the split breast flap was performed. Evident in the picture are skin staples present in the upper wound margin and a layer of antiseptic cream applied to the wound margins

pectoralis major flaps and serratus anterior flaps $(3,13-16)$. The external oblique muscle of the abdomen was found to be ideal for transposition into defects below the fourth rib due to it being the largest and most superficial of the flat muscles of the abdominal wall; the donor defect was easily closed in a V-Y fashion (17). These muscle flaps provide bulk, protection, stabilization and good blood supply in the reconstructed region (18).

\section{Surgical technique}

The breast tissue harvesting technique is logical and easy to perform. It consists of an incision following the inframammary crease and further mobilization of the breast off the anterior chest wall in a cranial direction. This dissection is performed to a level superior to the nipple-areola complex. The breast is then split according to the requirements of the particular reconstruction. It is possible to split the breast from its central inferior margin to the superior most tip of the breast. The nipple-areola complex can be maintained or removed as required. One of the split 'halves' or portions of the breast is then used to close the donor defect, and the remaining 'split' section can be transposed either medially, as in the present reported case, or laterally, if the defect to be reconstructed is laterally situated. The split breast flap is an excellent provider of an abundance of local well-vascularized tissue.

The primary arterial supply is provided by the anterior perforating branches of the internal mammary artery and from the lateral thoracic artery. The anterior and posterior intercostal arteries further improve the vascularity. There is an abundance of anastomoses between these systems, with a slight anatomical variation as to which pattern actually dominates. The venous drainage occurs via vessels accompanying the main arterial supply.

7. Arnold PG, Pairolero PC. Surgical management of the radiated chest wall. Plast Reconstr Surg 1986;77:605-12.

8. Samuels L, Granick MS, Ramasastry S, Solomons MP, Hurwitz D. Reconstruction of radiation induced chest wall lesions. Ann Plast Surg 1933;31:399-405.

9. Korlof B, Nylen B, Olsson P, Skoog T, Strombeck J. Resection to the thoracic wall and local flap repair for recurrences of mammary carcinoma. Br J Plast Surg 1973;26:322-7.

10. Baue A. Total resection of the sternum. J Thorac Cardiovasc Surg 1963;45:559.

11. Rees TD, Conversr JM. Surgical reconstruction of defects of the thoracic wall. Surg Gynec Obstets 1965;121:1066-72. 
12. Larson DL, McMurtrey MJ. Musculocutaneous flap reconstruction of chest wall defects: An experience of 50 patients.

Plast Reconstr Surg 1984:734-40.

13. Arnold PG, Pairolero PC. Use of pectoralis major muscle flap to repair defects of the anterior chest wall. Plast Reconstr Surg 1979;63:205-13.

14. Brown RG, Fleming WH, Jurkiewitz MJ. An island flap of the pectoralis major muscle. Br J Plast Surg 1977;30:161-5.

15. Dupont $\mathrm{C}$, Menard Y. Transposition of the greater omentum for reconstruction of the chest wall. Plast Reconstr Surg 1972;49:263-7.
16. Maruyama Y, Onishi K, Iwahira Y. Reconstructing chest wall with vertical abdominal fasciocutaneous flaps. Scand J Plast Surg 1986;20:79-83.

17. Hodgkinson DJ, Arnold PG. Chest wall reconstruction using the external oblique muscle. Br J Plast Surg 1980;33:216-20.

18. Meland NB, Ivy EJ, Woods JE. Coverage of chest wall and pelvic defects with the external oblique musculocutaneous flap. Ann Plast Surg 1988;21:297-302. 